\title{
Dynamic HV cables with AL conductors for floating offshore wind turbines: a cost and behavior comparative study
}

\author{
K. Grivas, A. Moraiti, G. Georgallis \\ Hellenic Cables, Olympioniki Tsiklitira 41,151 25 Maroussi, Athens, Greece
}

\author{
G. Rinaldi, P.R. Thies \& L. Johanning \\ Renewable Energy group, University of Exeter, Penryn Campus, Treliever Road, TR109FE, Penryn, \\ Cornwall, UK
}

\begin{abstract}
Floating Offshore Wind installations require high-voltage dynamic power cables to transmit the electricity generated from the devices to the offshore substation, before being exported to the onshore grid. High integrity, yet cost effective cable solutions are needed for this purpose. Whilst copper is the conventional choice of material due to its lower resistive losses, aluminium cores are increasingly being proposed for static power cables applications due to their reduced cost and weight. In this work, a comparative analysis of these two options in terms of costs and performance is presented. A numerical model evaluating the expected cable effective tensions and bending stresses, coupled with an aero-elastic and hydrodynamic model of a floating wind platform, is used to define the ultimate load conditions for various configurations. Results show the feasibility of cables with aluminium conductors for low weight, low cost and deep water applications, highlighting the advantages for floating offshore wind projects.
\end{abstract}

\section{INTRODUCTION}

Fixed foundations provide a viable solution for the support of offshore wind turbines. However, these kinds of structure are subject to limitations in terms of the water depth they can be installed in. Beyond $50-$ $60 \mathrm{~m}$, solutions fixed to the seabed become impractical and uneconomical. For this reason, a number of floating platforms have been proposed in order to host the wind device and overcome this limitation (The Carbon Trust 2015).

A number of innovations will be needed in order to satisfy the technical requirements of this novel kind of foundations, and to guarantee a cost effective production of electricity. Among these, the power cable will be one of the most important components. Its role is to guarantee that the electricity produced by the wind turbine is safely delivered to the offshore substation, from where it will then be transported onshore by means of a static export cable. In doing so, electrical losses have to be minimized, and the mechanical stresses due to the platform motions and environmental loads have to be withstood in their magnitude and number to avoid damages to the cable structure. For these reasons, dynamic power cables able to operate in extreme environments and to resist cyclical stresses and varying bending are needed.

Traditionally, due to its excellent conductivity properties, copper is the most widely used material for the core of power cables. However, while this material is perfectly suitable for fixed or shallow water applications, loads due to excessive cable weight potentially limits its use in deeper waters. Hence, substitute core materials are being investigated for dynamic power cables in deep waters.

Among these, aluminium has been identified as a suitable alternative thanks to its lower density (approximately 70\% lower than copper's density, i.e. $\rho_{\text {copper }} \sim=8.96 \mathrm{gr} / \mathrm{cm}^{3}$ and $\rho_{\text {aluminium }} \sim=2.7 \mathrm{gr} / \mathrm{cm}^{3}$ ) and lower specific cost. Although aluminium has a lower electrical conductivity than copper (approximately $61 \%$ IACS), this can be compensated by having a power cable with a larger cross sectional area, still achieving a cheaper and lighter solution. A suitable configuration for an aluminium power conductor cable has been identified in (Thies et al. 2019a), and its mechanical performance and load parameters assessed in (Thies et al. 2019b).

Expanding on this work, this paper aims at further investigating the suitability of aluminium $(\mathrm{Al})$ power cables as a substitute for conventional copper $(\mathrm{Cu})$ cores. Based on the implemented numerical case study to seek suitable cable configurations and estimate expected tension and bending stresses, this paper presents a cost comparative analysis against existing solutions.

The paper is organized as follows. In section 2, the methodology to implement the comparison, and assess the cost of the different cable materials, is outlined. In section 3 , the result of the comparative investigation are presented and explained, before being discussed in view of the wider implications for the floating offshore wind sector in section 4. Finally, conclusions are drawn in section 5 . 


\section{METHODOLOGY}

In order to obtain a fair comparative study, equivalent conductors have to be taken into account. Since aluminium and copper have different electrical conductivity, in order to obtain similar DC resistance ( 0.125 and $0.124 \Omega / \mathrm{km}$ respectively), different cross sections must be considered. Therefore, a 240 sq.mm aluminium conductor is compared to a 150 sq.mm copper conductor with respect to mechanical characteristics, cost and behavior under ultimate load conditions. The rationale for this choice is described in the following.

\subsection{Cost capabilities study}

An initial study has been conducted in order to investigate the capabilities of aluminium conductors for floating offshore wind farms applications (IRENA 2016). The investigated parameters were:

- No. of Wind Turbine Generators (WTGs) per string and WTGs' capacity.

- Effect of temperature (depending on where the WTG's will be placed) on current rating. Conductor's weight.

- Cost (based on material's current London Metal Exchange (LME) pricing.

The presented comparative cost study has been conducted considering a commercially available electrical conductor grade aluminium (AA 1350 Series). For aluminium alloys, alloys in which $(\mathrm{Al})$ is the predominant metal, a series with a wide range of applications is AA6000. Among all the alloys the most promising in terms of the mechanical characteristics is the 6101A alloy (6101A-T6, AlMgSi(A)). Nevertheless, AA6000 alloys exhibit significantly lower electrical conductivity (55\% International Annealed Copper Standard (IACS)) than the AA1000 (61\% IACS). Hence, usage of AA6000 would result in a larger cross-section in order to meet the current requirements compared to AA1000 and consequently would lead to a lower cost ratio. Therefore, for this study the AA1000 Series aluminium is considered as conductor. Under these circumstances, a cable solution with $240 \mathrm{~mm}^{2}$ aluminium conductor is chosen for comparison against its electrically equivalent of $150 \mathrm{~mm}^{2}$ copper conductor.

\subsection{Performance capabilities study - Numerical models}

A numerical study has been performed to investigate the load performance of a dynamic cable with aluminium conductor for deep water (100 $600 \mathrm{~m}$ ) Floating Offshore Wind (FOW) applications.

The subsea geometry of the cable can vary depending on the water depth and loading regimes (Clausen and Souza 2001). Some standard configurations are shown in Figure 1. In this paper, the lazy wave configuration has been adopted to compare the two different cable designs and demonstrate the aluminium conductor's capability to replace the conventional solution with copper for deep water applications. This configuration is succeeded with buoyancy floater to create a long radius curve in order to absorb the top-end (hang off) motion. Other configurations will be examined in future work to illustrate further potentialities.

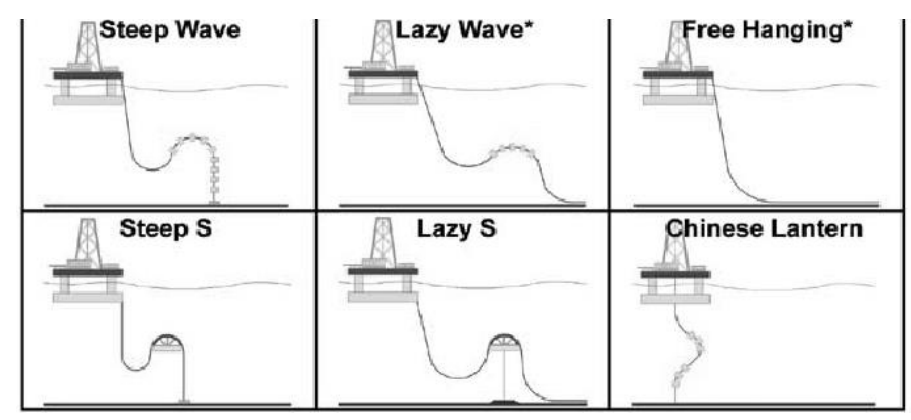

Figure 1. Typical dynamic cable configurations for floating offshore structures.

The mechanical load analysis for dynamic submarine power cables is commonly carried out in two distinctive steps:

1. Global load analysis: The forces and motions acting on the power cable, induced through the combined effect of the metocean environment and the aero - hydrodynamic response of the floating structure, are estimated.

2. Local analysis: The local stresses (within the cross-section) of the cable are determined.

FOW installations are modelled through a combined model that simulates both the aerodynamic and hydrodynamic load conditions. The main features and parameters for both models are briefly described hereinafter.

The aerodynamic model employs the open access code FAST (Jonkman 2005). The aerodynamic and structural properties of the wind turbine are represented through a suite of sub-models in order to estimate the wind turbine loads in time-domain simulations. For the scope of this study, a 5MW NREL reference turbine has been employed.

The hydrodynamic modelling is carried out employing the commercial marine dynamics software OrcaFlex (2019) from Orcina. This software is a three-dimensional non-linear time domain finite element program, which employs a lumped mass 
element approach to solve the dynamic behavior of line objects, i.e. sections of the cable. The cable is represented as a series of segments with a node at each end. While the segments carry the axial and torsional charecteristics, all other properties (mass, weight, buoyancy etc.) are lumped into the nodes. Forces and moments are applied at the nodes, while the segments are treated as straight massless elements with axialand torsional spring- damping characteristic. The end of each segment additionally carries a rotational spring-damping term that models the bending characteristics. The computational model has been set up, comprising the following elements:

a. The semisubmersible platform OC4 (Robertson et al. 2014) with translational and rotational movements.

b. The dynamic submarine power cable.

c. The mooring lines.

d. An attachment point at the bottom center of the platform, representing the hang off point and modelled as flexible joint with three rotational degrees of freedom.

e. An anchor point on the seabed.

The simulation considers all geometric nonlinearities as the system geometry is recomputed at every time step. The integration time step was set to $0.02 \mathrm{~s}$, which is sufficiently small to capture high frequency responses and balances computational time and model accuracy. The simulation time was selected to be 3600 s with an initial time step of 400 s before $\mathrm{t}=0 \mathrm{~s}$ to smooth out the transient effects. The tension forces are computed first, followed by the bend moment, shear forces, torsion moment and the total load.

Convergence and sensitivity analyses have been performed in (Thies et al. 2019a). Since the scope of the present work is to investigate at an early stage whether or not a cost effective solution proposing aluminium conductor would be appropriate for floating offshore wind application, especially in deep waters all these parameters were kept the same.

Figure 2 depicts a wireframe overview of the main system components, including the floating semisubmersible platform, maintaining station through three mooring lines at 120 degrees spread and the dynamic cable in a Lazy Wave configuration.

Table 1 summarizes the cable properties for the aluminium core design. These values were used as reference values and all results presented in the next section were compared to these in order to validate the integrity of the proposed aluminum conductor's design to withstand both the environmental and the floater's motion load conditions.

Table 2 shows the three modelled load cases, which were chosen to allow a comparison with the copper conductor cable simulated in (Thies et al. 2019a). Metocean date from the WaveHub site in the UK (Van Nieuwkoop et al. 2013) is chosen as conceptual design site. It should be noted that the combined wave / water depth and current conditioned do not resemble a specific site, but are used to operate a representative model. Wind speed varies between 9 - $25 \mathrm{~m} / \mathrm{s}$ to capture lower, medium and higher operational wind speeds. More sites will be investigated in future work to enrich the portofolio of cases for which the new cable design will be proposed.

All simulations were run for a water depth $\mathrm{D}=$ $200 \mathrm{~m}$, a sea state with significant wave height $\mathrm{H}_{\mathrm{s}}=$ $9 \mathrm{~m}$ and peak period $\mathrm{T}_{\mathrm{p}}=15 \mathrm{~s}$, representing the 100 year return period which describes the Ultimate Limit State (ULS).

Using an Intel R Xeon, $3.2 \mathrm{GHz}, 2$ cores, $128 \mathrm{~GB}$ RAM machine, using simulation parameters (3600s overall time; 0.02 s time step) each simulation solved in approximately 12 hours run time.

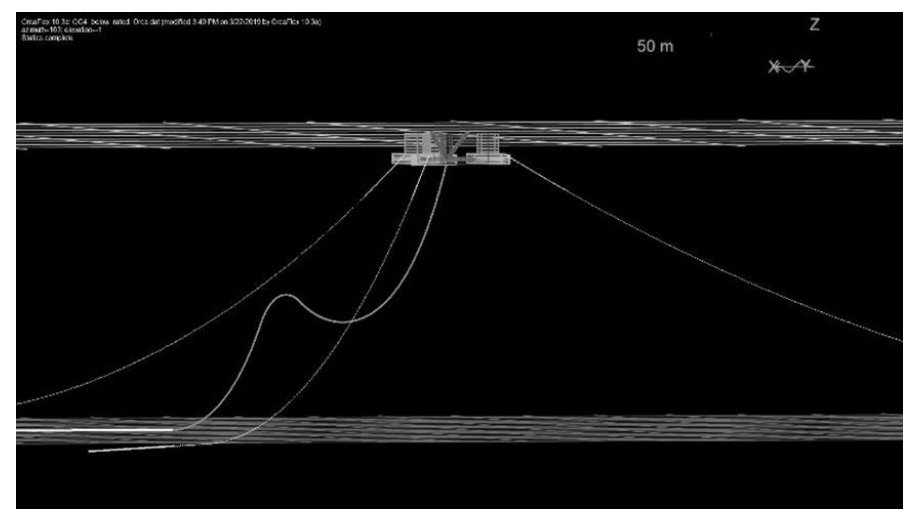

Figure 2. Overview of platform, cable and mooring configuration.

Table 1. Aluminium cable properties.

\begin{tabular}{|c|c|c|}
\hline $\begin{array}{c}\text { Parameter } \\
{[\text { unit] }}\end{array}$ & Symbol & Value \\
\hline $\begin{array}{c}\text { Static axial } \\
\text { strength }[\mathrm{kN}]\end{array}$ & Fmax & 56 \\
\hline $\begin{array}{c}\text { Minimum } \\
\text { bending radius } \\
{[\mathrm{m}]}\end{array}$ & MBR & 2.3 \\
\hline
\end{tabular}

Table 2. Overview of modelled environmental load cases. Each load case is modelled for 3600 s.

\begin{tabular}{|c|c|c|c|}
\hline Load Case & $\mathrm{H}_{\mathrm{s}}[\mathrm{m}]$ & $\mathrm{T}_{\mathrm{p}}[\mathrm{s}]$ & $\mathrm{V}[\mathrm{m} / \mathrm{s}]$ \\
\hline $\begin{array}{c}\text { Low rated } \\
\text { wind speed }\end{array}$ & 9.0 & 15 & 8.0 \\
\hline $\begin{array}{c}\text { Medium } \\
\text { wave speed }\end{array}$ & 9.0 & 15 & 15.0 \\
\hline $\begin{array}{c}\text { Upper limit } \\
\text { rated wind } \\
\text { speed }\end{array}$ & 9.0 & 15 & 25.0 \\
\hline
\end{tabular}




\section{RESULTS}

\subsection{Cost comparison}

The outcomes of this study, in terms of the requirements for different offshore wind farm sizes, are shown in Table 3. In this table, a typical current rating for a $66 \mathrm{kV}$ dynamic cable with respect to the capacity and number of Wind Turbine Generators (WTGs) is presented. $U_{o}$ represents the rated voltage phase to earth, $U$ the rated voltage phase to phase and $\mathrm{U}_{\mathrm{m}}$ the maximum voltage. $\mathrm{I}_{\max }$ stands for the maximum current the cable can transmit.

Moreover, in Table 4, current rating requirements of a $66 \mathrm{kV}$ dynamic cable are shown for different conductor cross sections for both $\mathrm{Cu}$ and the equivalent $\mathrm{Al}$ material.

Table 3. Current rating requirement of a $66 \mathrm{kv}$ dynamic cable with respect to the capacity and number of wind turbines.

\begin{tabular}{|c|c|c|c|c|}
\hline Parameter & \multicolumn{4}{|c|}{ Value } \\
\hline $\mathrm{U}_{\mathrm{o}} / \mathrm{U}\left(\mathrm{U}_{\mathrm{m}}\right)[\mathrm{kV}]$ & \multicolumn{4}{|c|}{$38 / 66(72.5)$} \\
\hline WTG Capacity [MW] & 6 & 8 & 10 & 12 \\
\hline $\mathrm{I}_{\max }[\mathrm{A}] /$ WTG & 55 & 74 & 92 & 110.5 \\
\hline
\end{tabular}

\begin{tabular}{|c|c|c|c|c|}
\hline $\begin{array}{c}\text { Number of WTGs / } \\
\text { string }\end{array}$ & \multicolumn{4}{|c|}{$\mathrm{I}_{\max }[\mathrm{A}]$ / string } \\
\hline 5 & 276 & 368 & 460 & 552.5 \\
\hline 8 & 442 & 589 & 737 & 884 \\
\hline
\end{tabular}

Table 4. Current rating of the $66 \mathrm{kV}$ dynamic cable with respect to conductor cross section for $\mathrm{Cu}$ and equivalent $\mathrm{Al}$.

\begin{tabular}{|c|c|c|}
\hline $\begin{array}{c}\text { Current Rating } \\
\text { Requirement } \\
{[\mathrm{A}]}\end{array}$ & $\begin{array}{c}\text { Cu conductor } \\
\text { cross-section } \\
{\left[\mathrm{mm}^{2}\right]}\end{array}$ & $\begin{array}{c}\text { Al conductor } \\
\text { cross-section } \\
{\left[\mathrm{mm}^{2}\right]}\end{array}$ \\
\hline 276 & 150 & 240 \\
\hline 368 & 150 & 240 \\
\hline 442 & 185 & 300 \\
\hline 460 & 300 & 500 \\
\hline 553 & 300 & 500 \\
\hline 589 & 630 & 800 \\
\hline 737 & 630 & 800 \\
\hline 884 & $800-1000$ & $*$ \\
\hline
\end{tabular}

* Large cross sections above $1400 \mathrm{~mm}^{2}$ - not preferred for $\mathrm{Al}$ to be used in inter-array cabling applications.

As shown in Table 3 and Table 4 for WTGs of 6 $12 \mathrm{MW}$ installed capacity, considering a power factor equal to 0.95 and the voltage level of $38 / 66(72.5) \mathrm{kV}$, the current requirements can be met by cable designs with both aluminium and copper conductors with cross-sections up to $1400 \mathrm{~mm}^{2}$. Consequently, power transmitting requirements can be met by dynamic cables with aluminium conductors.

As indicated in Table 5 a comparative weight and cost variation analysis (prices for $\mathrm{Cu}$ and $\mathrm{Al}$ are based on LME September 2019 prices) considering only the conductor materials for the same power transmission capability demonstrates a significant cost and weight advantage for cables with aluminium conductors.

Table 5. Current rating of the $66 \mathrm{kV}$ dynamic cable with respect to conductor cross section for $\mathrm{Cu}$ vs eq. $\mathrm{AL}$ and weight / cost ratios.

\begin{tabular}{|c|c|c|c|}
\hline $\begin{array}{c}\text { CU } \\
\text { conductor } \\
\text { cross- } \\
\text { section } \\
{\left[\mathrm{mm}^{2}\right]}\end{array}$ & $\begin{array}{c}\text { AL } \\
\text { conductor } \\
\text { cross- } \\
\text { section } \\
{\left[\mathrm{mm}^{2}\right]}\end{array}$ & $\begin{array}{c}\text { Weight } \\
\text { Ratio } \\
{[\mathrm{AL} / \mathrm{CU}]}\end{array}$ & $\begin{array}{c}\text { Cost } \\
\text { Ratio } \\
{[\mathrm{AL} / \mathrm{CU}]}\end{array}$ \\
\hline 150 & 240 & $48.4 \%$ & $19.6 \%$ \\
\hline 150 & 240 & $48.4 \%$ & $19.6 \%$ \\
\hline 185 & 300 & $49.7 \%$ & $20.1 \%$ \\
\hline 300 & 500 & $51.1 \%$ & $20.7 \%$ \\
\hline 300 & 500 & $51.1 \%$ & $20.7 \%$ \\
\hline 630 & 800 & $49.1 \%$ & $19.8 \%$ \\
\hline
\end{tabular}

Focusing on two equivalent cross sections, as presented in Table 6, both the weight and the cost -in terms of current LME prices (September 2019) for copper and aluminium - of a $240 \mathrm{~mm}^{2} \mathrm{Al}$ conductor is lower that the respective $150 \mathrm{~mm}^{2} \mathrm{Cu}$ conductor. A more detailed pricing analysis, not in the scope of this study since the main cost impact is from the conductor materials, could consider the cost of other cable materials, such as plastic and fillers, as well as associated process costs.

Overall, the $\mathrm{Al}$ conductor serves the needs of a low weight and low cost conductor to replace the conventional $\mathrm{Cu}$ one. 
Table 6. Weight and Cost comparison between $\mathrm{Cu}$ and $\mathrm{Al}$ conductor.

\begin{tabular}{|l|l|l|l|l|l|}
\hline Conductor & $\begin{array}{l}\text { Weight } \\
{[\mathrm{kg} / \mathrm{km}]}\end{array}$ & $\begin{array}{l}\text { Current } \\
\text { Material } \\
\text { Price } \\
{[€ / \mathrm{kg}]}\end{array}$ & $\begin{array}{l}\text { Total } \\
\text { Cost } \\
{[€ / \mathrm{km}]}\end{array}$ & $\begin{array}{l}\text { Weight } \\
\text { Variation } \\
{[\%]}\end{array}$ & $\begin{array}{l}\text { Cost } \\
\text { Variation } \\
{[\%]}\end{array}$ \\
\hline $\begin{array}{l}150 \mathrm{~mm}^{2} \\
\mathrm{Cu}\end{array}$ & 3822.1 & 5.91 & 22588 & 100 & 100 \\
\hline $\begin{array}{l}240 \mathrm{~mm}^{2} \\
\mathrm{Al}\end{array}$ & 1876.5 & 2.39 & 4485 & 38.9 & 19.1 \\
\hline
\end{tabular}

\subsection{Performance comparison}

In order to investigate the weight and cost reduction potential of aluminium over copper conductors, a 3-hr simulation time numerical study focusing on suitable cable configurations, seeking to estimate the expected cable tensions and Minimum Bending Radius (MBR) has been conducted. The maximum load conditions are assessed for an irregular sea state with significant wave height $\mathrm{Hs}=$ $9 \mathrm{~m}$ and $\mathrm{Tp}=15 \mathrm{~s}$.

The results are presented with a view towards the Minimum Bending Radius (curvature) that the cable has to withstand and the effective tension along the length of the cable. Both parameters indicate, whether the cable design and configuration are suitable, comparing cable design properties for the selected modelled load conditions.

Figure 3 depicts the minimum, mean and maximum tensions along the entire length of the cable (arc length $=0$ corresponds to the cable hang off point at the platform and arc length $=400 \mathrm{~m}$ is at the touch down point (TDP) on the seabed). Throughout the simulated load case the cable is not subjected to compression (i.e. negative minimum tensions), satisfying an important design criterion. It can also be observed that the highest tension is located at the cable hang off point at the platform (arc length $=0$ ). The tension peak mid-arc $(\sim 220 \mathrm{~m})$ aligns with the location of the Lazy Wave arc. The visible discrete steps mid-arc, are caused by the discrete floatation buoy elements. The rated axial strength $(56 \mathrm{kN})$ is not reached at any point during the ULS case $\left(\mathrm{F}_{\max }=36\right.$ $\mathrm{kN})$, with a mean cable tension of $\left(\mathrm{F}_{\text {mean }}=30 \mathrm{kN}\right)$ at the cable hang off.
Figure 3. Range graph plot showing minimum, mean and maximum cable tensions for configuration during ULS simulation $\left(\mathrm{H}_{\mathrm{s}}=9 \mathrm{~m}, \mathrm{~T}_{\mathrm{p}}=15 \mathrm{~s}\right)$. Arc length $=0$ corresponds to the cable hang off at the platform.

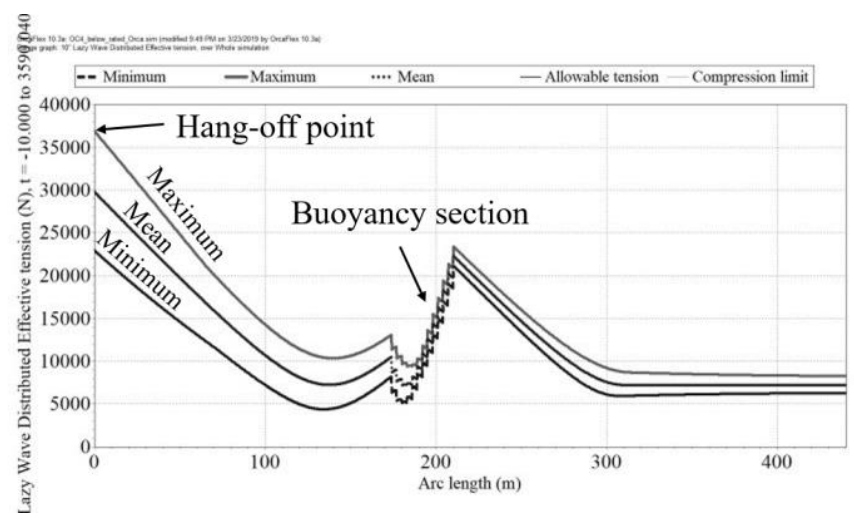

Figure 4 displays the cable curvature along the cable length, showing the $\mathrm{min} / \mathrm{mean} / \mathrm{max}$ curvature the cable is subjected to. The highest curvature is located at the physical Lazy Wave peak $(0.195$ $\mathrm{rad} / \mathrm{m})$, but is a factor of 2.2 below the rated cable curvature $(0.43 \mathrm{rad} / \mathrm{m})$.

Figure 4. Range graph plot showing minimum, mean and maximum cable curvatures during ULS simulation $\left(H_{s}=9 m, T_{p}\right.$ $=15 \mathrm{~s}$ ). Arc length $=0$ corresponds to the cable hang off at the platform. The allowable curvature is $\kappa=0.195 \mathrm{rad} / \mathrm{m}$.

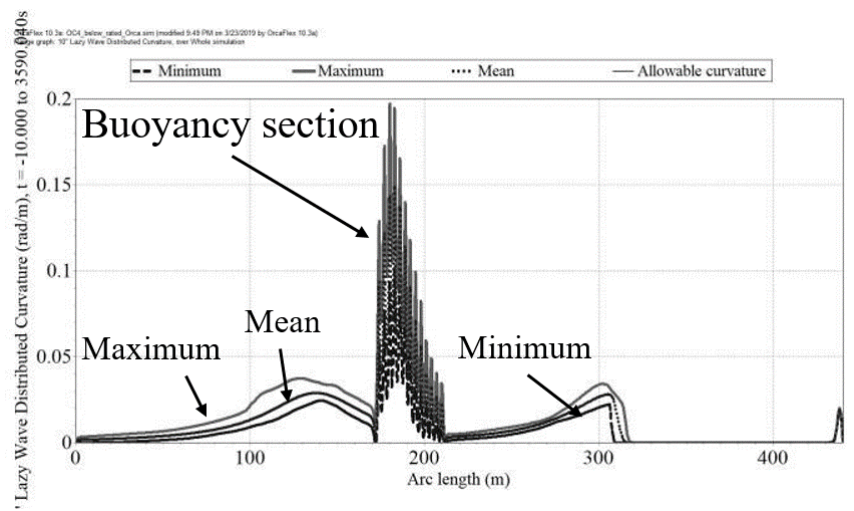

The results indicate that the cable design criteria regarding tension, compression and MBR constraints are met for the chosen configuration and the modelled selection of load cases.

The objective for this study was to compare the copper and aluminium conductor cable behaviour for the same floating offshore wind installation. A direct comparison of key parameters is given in Table 7 . 
Table 7. Comparison of aluminium and copper cable load parameters for selected simulations, water depth $=200 \mathrm{~m}$.

\begin{tabular}{|c|c|c|c|c|}
\hline $\begin{array}{c}\text { Parameter } \\
\text { [unit] }\end{array}$ & Symbol & $\begin{array}{c}\mathrm{Al} \\
\text { conductor }\end{array}$ & $\begin{array}{c}\mathrm{Cu} \\
\text { conductor }\end{array}$ & $\begin{array}{c}\text { Ratio } \\
(\mathrm{Al} / \mathrm{Cu}) \\
{[-]}\end{array}$ \\
\hline $\begin{array}{c}\text { Max cable } \\
\text { tension [kN] }\end{array}$ & Fmax & 36 & 48 & 0.75 \\
\hline $\begin{array}{c}\text { Mean cable } \\
\text { tension [kN] }\end{array}$ & Fmean & 30 & 41 & 0.73 \\
\hline $\begin{array}{c}\text { Minimum } \\
\text { bending } \\
\text { radius [m] }\end{array}$ & MBR & 5.1 & 6.25 & 0.82 \\
\hline
\end{tabular}

Keeping all model parameters constant, including a fixed water depth of $D=200 \mathrm{~m}$, it can be seen that the aluminium cable, configured for the same voltage capacity $(66 \mathrm{kV})$ is able to reduce the max cable tension at the hang off $(-25 \%)$ and the mean cable tension $(-27 \%)$. The necessary trade-off in the design is an increased cable diameter $(+60 \%)$. The modelled MBR that the cable has to withstand is also lower for the Al conductor cable. Similar results have been found for larger aluminium conductor sizes.

These results indicate that the design envelope can be achieved for $\mathrm{Al}$ conductor cables, offering benefits in deeper water of $200 \mathrm{~m}$, as shown in this paper and potentially beyond.

The benefits brought by the use of $\mathrm{Al}$ conductor cables will be even larger for increased water depths, relieving both maximum and mean tension at the hang off point.

\section{DISCUSSIONS}

A $240 \mathrm{~mm}^{2}$ aluminium conductor is compared to a $150 \mathrm{~mm}^{2}$ copper conductor with respect to cost and behavior characteristics under ultimate load conditions.

Larger cross-sections of aluminium conductors were also compared to the corresponding copper conductor designs (in terms of electrical DC resistance) and the same pattern in the results has been observed. Within the scope of the present work only the results for the $240 \mathrm{~mm}^{2}$ aluminium and $150 \mathrm{~mm}^{2}$ copper conductors are presented in order to highlight the advantage of the aluminium conductor over copper. Al conductors have the potential to facilitate cable designs for increasingly deeper water FOW applications.

The results produced in this paper show that $\mathrm{Al}$ conductor cables present numerous advantages in deep water applications for offshore renewable energy. A more detailed cost analysis, including variation of insulation, armouring and filling materials, as well as their respective processing and price sensitivities, would alter the estimated weight and cost ratios to a small degree, but is unlikely to change the overall conclusion.

\section{CONCLUSIONS}

So far, the conventional solution for dynamic application in cable designs are copper conductors. Advances in light weight dynamic cables are needed to reduce loads and achieve reliable and cost-effective cable systems in Floating Offshore Wind farms.

This work presents the main results regarding the load performance of a dynamic power cable with aluminium conductor, seeking to reduce the cable weight to facilitate increasingly deeper water FOW installations. Based on the selected load cases and coupled aerodynamic - hydrodynamic load modelling a reduction of the ULS tensions is found, regarding both the maximum tension at the hang off, as well as the mean cable tension (-25\% and $-27 \%$ respectively). This is an encouraging outcome, as any load reliefs can propagate into the design of hang offs and connectors. The same reduction pattern has been observed for the MBR that the proposed cable design can withstand.

Thus, the design, testing and demonstration of $\mathrm{Al}$ conductor cable for FOW applications has the potential to contribute to a reduction in levelized cost of electricity for this technology.

\section{ACKNOWLEDGMENTS}

This project has received funding from the European Union's Horizon 2020 research and innovation programme under the project "FLOTANT", grant agreement 815289, https://flotantproject.eu/ .

P.R. Thies would also like to acknowledge the support though the EPSRC Supergen ORE Hub [EP/S000747/1].

\section{REFERENCES}

The Carbon Trust. 2015. Floating Offshore Wind: Market and Technology Review.

Thies, Philipp R et al. 2019a. "Load and Fatigue Evaluation for $66 \mathrm{Kv}$ Floating Offshore Wind Submarine Dynamic Power Cable." In 10th International Conference on Insulated Power Cables, Paris, 6-11.

. 2019b. "Performance Evaluation of Dynamic HV Cables with Al Conductors for Floating Offshore Wind Turbines." In 2nd International Offshore Wind Technical Conference (IOWTC), St. Julian's, Malta, 6-10. 
IRENA. 2016. "Floating foundations": A game changer for offshore wind power." International Renewable Energy Agency, Abu Dhabi.

"FAST User's Guide", NREL/EL-500-38230. National Renewable Energy Laboratory 2005. J. Jonkman, M. Buhl.

Orcina, 2019. OrcaFlex User Manual: OrcaFlexVersion 10.3 b. Daltongate Ulverston Cumbria, UK.

A. Robertson et al. 2014 "Definition of the Semisubmersible Floating System for Phase II of OC4", NREL/TP-500060601. National Renewable Energy Laboratory.

T. Clauzen and R. Souza 2001 "Dynamic risers key component for deep water drilling, floating production. Offshore magazine.

JCC. Van Nieuwkoop et al. 2013 "Wave resource asseement along the Cornish coast (UK) from a 23-year hindcast dataset validated against buoy measurements" Renewable Energy, vol. 58, pp. $1-14$. 